\title{
Sex-Related Adaptation to Disuse-Induced Skeletal Muscle Wasting
}

\author{
Toshinori Yoshihara* and Hisashi Naito \\ Graduate School of Health and Sports Science, Juntendo University, Japan
}

*Corresponding author: Toshinori Yoshihara, Graduate School of Health and Sports Science, Juntendo University, 1-1 Hirakaga-

kuendai, Inzai, Chiba 270-1695, Japan

\begin{tabular}{|c|c|}
\hline ARTICLE INFO & ABSTRACT \\
\hline & Males and females have some key different physiologies and hormonal profiles. These \\
\hline Published: 㓞 February 12, 2019 & $\begin{array}{l}\text { differences sometimes impact on muscle adaptation to various extracellular stimuli, in- } \\
\text { cluding muscle disuse. For example, some investigators reported that muscles in women }\end{array}$ \\
\hline $\begin{array}{l}\text { Citation: Toshinori Yoshihara, His- } \\
\text { ashi Naito. Sex-Related Adaptation } \\
\text { to Disuse-Induced Skeletal Muscle } \\
\text { Wasting. Biomed J Sci \& Tech Res } \\
\text { 14(3)-2019. BJSTR. MS.ID.002546. }\end{array}$ & $\begin{array}{l}\text { had a greater response to disuse than men. This suggests that disuse-induced skeletal } \\
\text { muscle loss may be sex-specific; however, current evidence is limited and the underly- } \\
\text { ing mechanisms responsible for this difference remain unclear. Nonetheless, growing ev- } \\
\text { idences from human and animal studies are showing that there are sex-related differences } \\
\text { in adaptation to muscle disuse, and the FoxO3a signaling pathway may be associated with } \\
\text { this phenomenon. Moreover, sex may affect unloading-induced functional neuromuscular }\end{array}$ \\
\hline $\begin{array}{l}\text { Keywords: Sex Specific Differences; } \\
\text { Muscle Atrophy; Neuromuscular Ad- } \\
\text { aptation; Forkhead Box O Signaling }\end{array}$ & $\begin{array}{l}\text { adaptations during disuse. This review summarizes sex-specific differential responses to } \\
\text { muscle disuse in humans and provides potential mechanisms for such differences in the } \\
\text { response to disuse-induced skeletal muscle wasting. }\end{array}$ \\
\hline
\end{tabular}

\section{Introduction}

Sex-related differences are well known in body composition [1], hormone concentrations [2], muscle fiber type composition [3], and substrate utilization [4]. These differences could affect muscle responses and adaptations to various extracellular stimuli such as exercise [5]. Importantly, some investigators reported that muscles in women have a greater response to disuse $[6,7]$.

The goals of this review are:

a) to summarize sex-specific differences in responses to muscle disuse in humans, and

b) to discuss the underlying mechanisms responsible for sex-related differences in skeletal muscular wasting.

\section{Sex-Specific Differences to Muscle Disuse in Humans}

Information on sex-specific differences in muscle adaptation to disuse is still limited. However, some investigators report that women have a greater response to muscle disuse than men. For example, Shackelford et al. [7] demonstrated that 17 weeks of horizontal bed rest induced a greater reduction in whole muscle volume in women $(-17.3 \%)$ as compared to men $(-10.7 \%)$ subjects. Moreover, in a side-by-side comparison, women showed a greater decline in thigh muscle size than men, even after shorter periods of bed rest (-21\% in 60 days in women vs. -17\% in 84 days in men) [811]. In contrast, Yasuda etal. [12] demonstrated that immobilizationinduced loss of knee extensor muscle strength was greater after 14 days of unilateral leg immobilization in women than in men despite a similar extent of atrophy at the myofiber and whole muscle levels. Moreover, after seven days of unloading by unilateral lower limb suspension, women experienced a greater strength decline during maximal isometric contractions, but not muscle mass, than men [13]. In addition, another study showed that the recovery of muscle strength from unloading was slower for women than for men [14]. These data indicate that the reduction in muscle strength and recovery period after disuse are greater in women regardless of the unloading period. However, sex differences are minimal in terms of a reduction in muscle size (2-4\%) in the first two weeks of unloading. Collectively, unloading (disuse)-induced skeletal muscle loss and weakness may be sex-specific. However, there is limited 
evidence supporting this possibility and it depends on the duration of disuse and the method of unloading in human skeletal muscle.

\section{Potential Mechanisms for Sex-Specific Differences in Muscular Wasting}

To date, the mechanisms responsible for sex-related differences in muscle wasting remain unclear, although some potential molecular changes have been identified that may explain the differences. A previous study demonstrated that women express higher levels of Fox03 mRNA than men [15]. FoxO3a transcription factors have been associated with two main catabolic systems: the ubiquitin-proteasome and autophagy-lysosome systems [16]. This suggests that differential FoxO3 signaling in response to unloading is responsible for the higher degree of skeletal muscle loss during disuse in females. Moreover, FoxO3 upstream molecules, such as Akt, heat shock protein (Hsp) 72, and myostatin, also exhibit sexspecific abundances or responses to several extracellular stimuli in human and rat skeletal muscles [17-19]. Indeed, our recent results indicate that seven days of hindlimb unloading induces a greater reduction in relative soleus muscle weight and fiber cross-sectional area in female than in male rats and is associated with a differential response to the FoxO3a/ubiquitin-proteasome pathway after hindlimb unloading [20].

Moreover, differential activation of the FoxO3a/ubiquitinproteasome pathway during hindlimb unloading may be associated with decreased Hsp72 expression and greater activation of myostatin signaling in female rat soleus muscle. Hsp72 inhibits Fox03a nuclear localization during muscle atrophy and, therefore, contributes to the maintenance of phosphorylated FoxO3a expression [21]. Thus, female animals tend to reduce Hsp levels during unloading, whereas males do not during short term (5-8 days) unloading. Because overexpression of Hsp72 in skeletal muscle prevents hindlimb unloading- and immobilization-induced atrophy in rodents [21,22], the higher levels of Hsp72 in male rats may be a positive regulator of skeletal muscle mass that downregulate FoxO3a-mediated protein degradation pathways. Our data also demonstrated sex-related differences in myostatin signaling following hindlimb unloading in rats [20]. Specifically, female rats exhibited a slight increase in myostatin expression with greater activation of downstream Smad2/3 signaling, compared to a non-significant decline in muscles from male rats following unloading. Myostatin is known as growth differentiation factor 8 and is a member of the transforming growth factor- $\beta$ (TGF- $\beta$ ) superfamily that acts as a negative regulator of muscle mass [23] Therefore, a greater response of myostatin signaling to various cellular stresses may have a negative effect on the maintenance of muscle mass during hindlimb unloading. In contrast, Maher et al. [24] suggested that there were no significant differences in myostatin mRNA and protein contents between healthy men and women subjects, at least during the resting condition. Nonetheless, recent evidence suggests that women show greater increases in
TGF- $\beta$ signaling in response to acute resistance exercise [17]. Thus, the increased response of myostatin signaling to various cellular stressors in females may negatively affect the maintenance of muscle mass during disuse, as well as following resistance training.

Little is known about the physiological mechanisms related to sex-specific differences in the reduction of muscle strength. Deschenes et al. $[13,25]$ have previously reported that women suffer more severe unloading-induced decrements in neuromuscular function than men. These may be due to the disparities in the capacity of the nervous system to activate contracting muscle and a greater diminution in the neural drive from the central nervous system in a woman. Moreover, in isolated rat soleus muscle, they also indicated that sex affected unloading-induced functional neuromuscular adaptations [26]. This suggested that the greater strength of male muscles was due to neuromuscular transmission efficiency as well as greater muscle mass. Additional studies are necessary to discover the potential mechanisms that cause a sex-specific reduction in muscle strength during disuse-induced skeletal muscle wasting.

\section{Summary and Conclusion}

In summary, growing evidence indicates that there are sexrelated differences in response to muscle disuse both in humans and animal models. However, the response depends on the duration and the method of unloading, at least in human skeletal muscle. Moreover, the precise mechanisms associated with sex-specific differences in disuse-induced muscle atrophy and weakness remain debatable. Therefore, additional research is required to clarify the mechanisms that cause sex-specific differences in response to disuse-induced skeletal muscle wasting. A better understanding of sex-specific changes in intracellular signaling that occur during muscle disuse would offer novel insights into the mechanisms that underlie sex-dependent differences in muscle wasting and may help develop treatments to minimize such wasting.

\section{Acknowledgment}

This work was partly supported by grants from the Institute for Environmental and Gender-Specific Medicinethe Institute for Environmental and Gender-Specific Medicine, Juntendo University (T. Yoshihara) and the Japan Society for the Promotion of Science (JSPS) KAKENHI Grant No. 17K01765 (T. Yoshihara).

\section{References}

1. Geer EB, Shen W (2009) Gender differences in insulin resistance, body composition, and energy balance. Gend Med 1: 160-75.

2. Callewaert F, Sinnesael M, Gielen E, Boonen S, Vanderschueren D (2010) Skeletal sexual dimorphism: relative contribution of sex steroids, GHIGF1, and mechanical loading. J Endocrinol 207(2): 127-134.

3. Haizlip KM, Harrison BC, Leinwand LA (2015) Sex-based differences in skeletal muscle kinetics and fiber-type composition. Physiology (Bethesda) 30(1): 30-39.

4. Roepstorff C, Steffensen CH, Madsen M, Stallknecht B, Kanstrup IL, et al. (2002) Gender differences in substrate utilization during submaximal 
exercise in endurance-trained subjects. Am J Physiol Endocrinol Metab 282(2): E435-447.

5. Ivey FM, Roth SM, Ferrell RE, Tracy BL, Lemmer JT, et al. (2000) Effects of age, gender, and myostatin genotype on the hypertrophic response to heavy resistance strength training. J. Gerontol. A. Biol. Sci. Med. Sci. 55(11): M641-648.

6. Ploutz Snyder L, Bloomfield S, Smith SM, Hunter SK, Templeton K, et al. (2014) Effects of sex and gender on adaptation to space: musculoskeletal health. J Womens Health (Larchmt) 23(11): 963-966.

7. Shackelford LC, LeBlanc AD, Driscoll TB, Evans HJ, Rianon NJ, et al. (2004) Resistance exercise as a countermeasure to disuse-induced bone loss. J Appl Physiol (1985) 97(1): 119-129.

8. Trappe S, Creer A, Minchev K, Slivka D, Louis E, et al. (2008) Human soleus single muscle fiber function with exercise or nutrition countermeasures during 60 days of bed rest. Am J Physiol Regul Integr Comp Physio 294(3): R939-947.

9. Trappe S, Creer A, Slivka D, Minchev K, Trappe T (2007) Single muscle fiber function with concurrent exercise or nutrition countermeasures during 60 days of bed rest in women. J Appl Physiol 103(4): 1242-1250.

10. Trappe S, Trappe T, Gallagher P, Harber M, Alkner B, et al. (2004) Human single muscle fibre function with 84 day bed-rest and resistance exercise. J Physiol 557(Pt 2): 501-513.

11. Trappe TA, Burd NA, Louis ES, Lee GA, Trappe SW (2007) Influence of concurrent exercise or nutrition countermeasures on thigh and calf muscle size and function during 60 days of bed rest in women. Acta Physiol (Oxf) 191(2): 147-159.

12. Yasuda N, Glover EI, Phillips SM, Isfort RJ, Tarnopolsky MA (2005) Sexbased differences in skeletal muscle function and morphology with short-term limb immobilization. J Appl Physiol (1985) 99(3): 10851092

13. Deschenes MR, McCoy RW, Mangis KA (2012) Factors relating to gender specificity of unloading-induced declines in strength. Muscle Nerve 46(2): 210-217.

14. Clark BC, Manini TM, Hoffman RL, Russ DW (2009) Restoration of voluntary muscle strength after 3 weeks of cast immobilization is suppressed in women compared with men. Arch. Phys. Med. Rehabil. 90(1): 178-180.

15. Welle S, Tawil R, Thornton CA (2008) Sex-related differences in gene expression in human skeletal muscle. PLoS ONE 3(1): e1385.

ISSN: 2574-1241

DOI: 10.26717.BJSTR.2019.14.002546

Toshinori Yoshihara. Biomed J Sci \& Tech Res

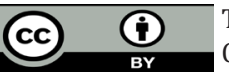

This work is licensed under Creative Commons Attribution 4.0 License

Submission Link: https://biomedres.us/submit-manuscript.php
16. Mammucari C, Schiaffino S, Sandri M (2008) Downstream of Akt: Fox03 and mTOR in the regulation of autophagy in skeletal muscle. Autophagy 4(4): 524-526.

17. Liu D, Sartor MA, Nader GA, Gutmann L, Treutelaar MK, et al. (2010) Skeletal muscle gene expression in response to resistance exercise: sex specific regulation. BMC Genomics 11: 659.

18. West DW, Burd NA, Churchward Venne TA, Camera DM, Mitchell CJ, et al. (2012) Sex-based comparisons of myofibrillar protein synthesis after resistance exercise in the fed state. J Appl Physiol (1985) 112(11): 18051813.

19. Voss MR, Stallone JN, Li M, Cornelussen RN, Knuefermann P, et al. (2003) Gender differences in the expression of heat shock proteins: the effect of estrogen. Am J Physiol Heart Circ Physiol 285(2): H687-H692.

20. Yoshihara T, Natsume T, Tsuzuki T, Chang SW, Kakigi R, et al. (2018) Sex differences in forkhead box 03a signaling response to hindlimb unloading in rat soleus muscle. J Physiol Sci.

21. Senf SM, Dodd SL, McClung JM, Judge AR (2008) Hsp70 overexpression inhibits NF-kappaB and Foxo3a transcriptional activities and prevents skeletal muscle atrophy. The FASEB journal: official publication of the Federation of American Societies for Experimental Biology 22(11): 3836-3845.

22. Miyabara EH, Nascimento TL, Rodrigues DC, Moriscot AS, Davila WF et al. (2012) Overexpression of inducible 70-kDa heat shock protein in mouse improves structural and functional recovery of skeletal muscles from atrophy. Pflugers Arch. 463(5): 733-741.

23. Elkina Y, von Haehling S, Anker SD (2011) The role of myostatin in muscle wasting: an overview. J Cachexia Sarcopenia Muscle 2(3): 143151.

24. Maher AC, Fu MH, Isfort RJ, Varbanov AR, Qu XA, et al. (2009) Sex differences in global mRNA content of human skeletal muscle. PLoS ONE 4(7): e6335.

25. Deschenes MR, McCoy RW, Holdren AN, Eason MK (2009) Gender influences neuromuscular adaptations to muscle unloading. Eur J Appl Physiol 105(6): 889-897.

26. Deschenes MR, Leathrum CM (2016) Gender-specific neuromuscular adaptations to unloading in isolated rat soleus muscles. Muscle Nerve 54(2): 300-307.

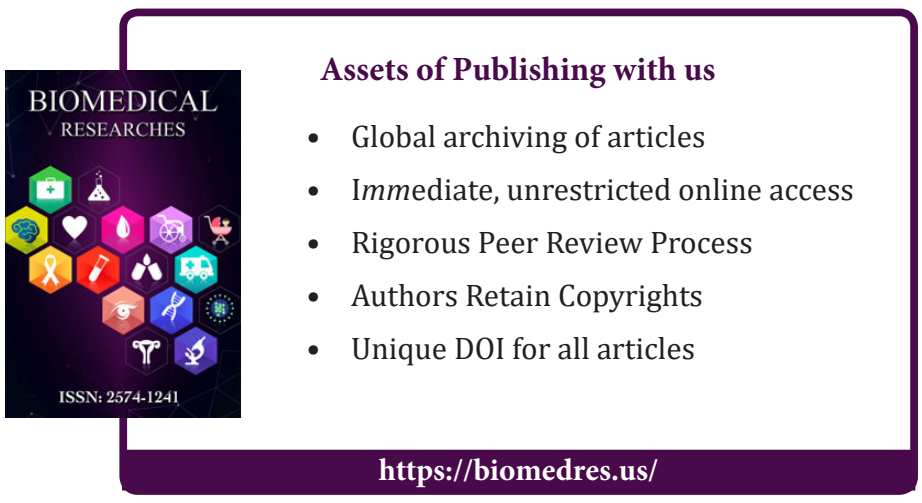

